\title{
Blogging Evolution
}

\author{
Adam M. Goldstein
}

Published online: 4 July 2009

(C) Springer Science + Business Media, LLC 2009

\begin{abstract}
A weblog ("blog") is an publication on the World Wide Web in which brief entries are displayed in date order, much like a diary or journal. I describe the general characteristics of blogs, contrasting blogs with other of WWW formats for self-publishing. I describe four categories for blogs about evolutionary biology: "professional," "amateur," "apostolic," and "imaginative." I also discuss blog networks. I identify paradigms of each category. Throughout, I aim to illuminate blogs about evolutionary biology from the point of view of a user looking for information about the topic. I conclude that blogs are not the best type of source for systematic and authoritative information about evolution, and that they are best used by the information-seeker as a way of identifying what issues are of interest in the community of evolutionists and for generating research leads or fresh insights on one's own work.
\end{abstract}

Keywords Blog • Weblog • World Wide Web • Digital publishing $\cdot$ Evolutionary biology $\cdot$ Evolution

Weblogs ("blogs") offer a deeply rewarding online experience because they provide a rich mix of expert opinion and instruction, diary-like personal narrative, journalism, and online community; but for just these reasons, they can be particularly tricky to understand, assess, and discover. In this review of blogs about evolution, I first make a few remarks about the nature of blogs and blogging intended to help Internet users

\footnotetext{
A. M. Goldstein $(\bowtie)$

Department of Philosophy, Iona College,

715 North Avenue New Rochelle,

NY 10801, USA

e-mail: agoldstein@iona.edu
}

take the greatest advantage of them; then I describe blogs about evolution exemplifying some of the important characteristics of evolution blogs more generally. I conclude by reflecting on the nature of evolution blogs and their usefulness as a source of information about evolutionary science.

\section{What is a Blog?}

"Blog" is an abbreviated form of "weblog," a compound of "web" and "log." Attending to the latter-"log"- suggests the central distinguishing characteristic of a blog: New content is posted ${ }^{1}$ in date order. Like a journal or online diary, the blogger or bloggers share thoughts, opinions, and feelings as they develop. Some uses of "blog" imply that blogs are generally intended to be controversial. Many are, particularly those about politics or pop culture, but creating controversy is not essential to the genre: As will be seen below, many blogs about evolution are intended to provide information, steering away from the controversies over creationism and intelligent design.

Beyond the central distinguishing characteristic of being published in date order, there is little else that unifies the enormously diverse world of blogs: Describing the range of topics addressed by blogs presents a

\footnotetext{
1"Post," as in "blog post," is an important term. The noun form of "post" refers to any content added to a blog intended to appear on the blog as a single, integral contribution to it. One of the dateordered entries, analogous to an entry one might make in a diary, is a post, and a user comment responding to a blog post is also a post. The verb form of "post" refers to the act of making a post, as in, "I will post tomorrow afternoon."
} 
task similar in scale to that of naming and describing all the species. Nonetheless, there are some broad classes of characteristics that may be used to describe the constituents of the "blogosphere."

Frequency of Updates Some blogs are updated several times a day, some daily, and some at highly irregular intervals, perhaps once a week or several times a month. Some are updated so rarely that they appear abandoned. In general, blog readers can expect the frequency of posts to a given blog to vary.

Tone and Style Bloggers take on a persona. Some are strident, overstating their case for maximum effect. Others are sober, suggesting an author interested in a measured assessment of facts and arguments. Still others are chatty and friendly. For this reason, there is no one writing style characteristic of the blogosphere. Some write on technical subjects in a professional manner, while others write in an unedited, stream-ofconsciousness style meant to build close personal contact with the reader and to convey initial and perhaps uncorrected reactions to new developments in areas of concern to the blogger. As with the frequency of posts, blog readers should expect the tone of a blog to shift as the blogger addresses different topics, changes moods, or comes to develop strong feelings about a given issue.

Media Formats Blogging software makes it easy for contributors to post or link to images, audio files, and videos. Links to other web pages are common as well, making the blog a starting point for finding related sites. The importance of links for building online community and for discovering new blogs is discussed below.

Topical Agenda or Subject-Area Focus Most blogs focus on a particular topic or subject area, giving the blogger a platform for sharing opinions, pointing out new resources, or commenting on new developments in the blog's area of focus. This focus may arise naturally. A scientist interested in a given topic may find himor herself writing about it more than about others, though not intending for the blog to focus on that topic. Many blogs are explicitly partisan, advancing a cause or particular point of view. This can create difficulty for those new to a blog's topic. The informal nature of the blogosphere allows broad scope for biting sarcasm that can be difficult to identify for someone unfamiliar with the subject matter. Readers new to a controversial topic are advised to read carefully and to reserve judgment about a blogger's position until reading several posts and browsing other blogs about the same subject.

Number of Contributors Many blogs present a diversity of views about an issue or subject area by publishing contributions from a team of bloggers, each writing independently. For instance, a group of film critics might contribute to a common blog of film reviews, building up a record of their range of responses to new films. Blogs that post material from contributors in different geographic areas, institutions, or disciplines can be particularly intriguing and informative. Some blogs offer what might be thought of as time-lapse snapshots of the research process. Researchers working on the same project contribute to a group blog, each reporting progress on his or her part of the work and posing questions for other group members. This facilitates communication among members of the research team and informs others doing similar work about the group's approaches and interim results.

Online Community Building Blogs are so tightly linked with one another and with their audiences that reading a blog should be understood as exploring the blogosphere as a whole. A single blog is a microcosm of all. Because blog publishing technology makes it so easy to integrate other Internet materials directly into blog posts, bloggers draw one another, their audiences, and the creators of other Internet resources into dialog and controversy. Some of the mechanisms by which online community building is achieved among bloggers include the following.

- Blog posts often present images, audio, or video stored elsewhere on the Internet. For instance, a news provider such as a wire service might post a video of an interview on its own home page; the blogger embeds a video player in a blog post so that users can watch the interview without leaving the blog or even being aware that the video originates elsewhere. Of course, the blogger would be expected to indicate the source of the video to avoid giving the impression that he or she created it.

- Many bloggers comment on each others' posts, integrating links to one another's work directly into the text of their responses to one another. This creates a network of cross-references among blogs. While this can lead to links among blogs whose contributors share views, it is often a way to learn about opposing views.

- Readers can often comment on posts, and some bloggers respond to reader comments, either by posting a response in a space provided on the blog for this purpose or by addressing them in a new blog entry.

- Bloggers will usually list links to their favorite blogs or to those that are of particular importance. The list of blogs, often called a "blogroll," is often 
presented as a part of the global navigation of a blog, that is, it appears in a fixed location for easy access as users browse blog content.

- Reaching into the "non-virtual" world, blogs often supply a list of recommended books and movies or a list of those recently read or viewed. Links to bookseller, publisher, and author web sites enhance these lists. Like the blogroll, these lists usually have a prominent place in a blog's global navigation scheme.

Keyword Indexing for Blog Posts Virtually all bloggers create keywords describing the content of each post. For instance, a paleontologist might tag some posts with "vertebrates" and others with "evolutionary theory." This permits readers to locate posts on a given topic without having to work through posts in the order in which they were created.

Bloggers do not draw upon a common stock of keywords. This means that a given topic might be indicated by different bloggers using different keywords. "Evolution," "evolutionary theory," and "evolutionary biology" might be used by different bloggers for posts about the same topics. Readers are urged to explore.

I would now like to address two formats for selfpublishing online that are distinct from blogs. By doing so, I hope that readers will gain further insight into the blog as essentially date-ordered, in contrast with microblogs and social networking sites.

Microblogging As new as it is, the blog has begun diversifying, or at least it is possible to identify species of online publishing related to the blog, if not in the same category. The essential characteristic of a microblog is that its "posts" are short—on the order of 100-200 characters. Twitter.com is the best known publisher of microblogs today. The brevity of microblog posts severely restricts the amount of information they can convey, of course, but microbloggers make up for this by posting at high frequency, some posting every minute or more, creating a nearly real-time account of the blogger's thoughts and activities. Those writing about themselves on microblogs create a public record of their lives at a scale more minute than previously possible; those microblogging about finance or technology document events faster than traditional reporters. If journalists write the first draft of history, the microblogger does the initial brainstorming.

Software exists for personal computers but also for cell phones and other handheld devices that display microblog posts as soon as they are entered. The rapid appearance of microblog entries on the display of these software packages and on the Twitter.com web site results in a narrow column of text that rapidly scrolls down the user's screen as new "posts" appear. This ticker-like appearance is reflected in a term generally applied to the microblog: "feed." Rather than "viewing so-and-so's microblog," one will "follow so-and-so's twitter feed."

No twitter feeds are reviewed in this article, with information about them being provided mainly for the purpose of alerting readers to the phenomenon. Although they are similar to blogs because new content is presented chronologically, the accelerated pace with which it appears and its brevity distinguish microblogs sufficiently from blogs so that the former constitute a separate topic, perhaps to be addressed in a successor to this paper.

Social Networking vs. Blogging Social networking web sites are another important Internet publishing phenomenon distinct from blogs. The central distinguishing elements of a social networking site are that (a) its users create online identities ("profiles"), which (b) they are able to link with those of other users so that (c) users of profiles linked to a common profile are visible to one another, linked by that profile. This results in the creation of a network. For instance, suppose that $A$ and $B$ are friends, and link their profiles. Suppose also that $A$ is friends with $C$, and the two link their profiles. Now, $B$ will be linked by $A$ to $C$, extending $B$ 's online social group. Because $B$ knows $A$, it is reasonable for $B$ to presume that she $(B)$ and $C$ will have something in common, if nothing more than affection for their common friend.

User profiles can be quite rich in content, offering users a way to describe almost every part of their lives and to post photos, music, and videos. facebook.com exemplifies this. In contrast, profiles might also be focused on a particular aspect of the users' activities and interests. For instance, profiles on a social networking site for scientists might only contain information about their education, professional history, publications, current research, and general areas of interest in science. This would provide a mechanism by which ornithologists (for instance) might find one another and meet more. Unless there is some expectation that users can contact one another independently of the network, profiles will most likely provide a messaging system. As well, social networking sites can provide a means for users to post messages, photos, or links to one another's profiles or to their own, these posts appearing on all linked profiles.

While one could use a social networking site to keep one's friends and colleagues informed about new developments, they are not primarily designed for this. 
Publishing diary-like, sequential posts is a small part of their intended use, which, as discussed above, is to create networks of user profiles. Much of the information on the user profile is static, or else changed only rarely, and when it is changed, no record of its past state is kept, and there is no expectation that changes to a profile represent developments or build on what was there before. The mail messages and networkwide messages are on the order of the microblog's in size; accordingly, the writing and message-reading tools on social networking sites are not particularly sophisticated. Moreover, a user's new network-wide messages appear alongside those of others, diluting the impact of those by any given user.

\section{Creating and Publishing Blogs}

Understanding how blogs are created can be useful for blog readers, even if they do not wish to create blogs of their own. The professional and attractive design, ease of use, expressive typography, and broad range of media types found in the blogosphere is indeed impressive. Could it really be that bloggers generally have a talent for web design and programming? Where do they find the time to put up new postings and to develop their sites?

As it happens, it is relatively easy to create an impressive-looking blog. Much as word processing software makes it easy for almost anyone to create professional-quality print documents, blogging platforms make it easy for almost anyone to build professional-quality blogs. As a general rule, blogs are created using software that is accessed by visiting a web site administered by the software's creators. At the site, the blogger logs in to his or her user account where he or she is able to select from a range of page layouts, type styles, and design elements. A new posting is created simply by typing it into a text-entry box, much as one might write an e-mail message; elements such as links to other sites or content such as videos and images are created by graphical and menu-driven interfaces that only require the blogger to enter a web address or file name. Text formatting and the organization of media content is handled automatically by the blog-creation software.

Some advanced bloggers build the software for creating and publishing their blogs into their own personal web sites, which they administer themselves. For the most part, however, blogs are published by one or another large blog-publishing service. Notable among these are Blogger.com and Wordpress.com. The former is owned by Google, and blogs built on this platform have an address that ends in "blogspot.com." Wordpress is an independent, open-source software development company.

Blogger.com and Wordpress.com offer blogging software and a World Wide Web address for their users, but some blog publishers go beyond this. The web sites Scienceblogs.com and Scientificblogging.com publish networks of blogs. Each of these publishers hosts blogs by many, many individuals blogging on a wide range of science and technology topics. The blogs on each site have a common architecture: Each has a common navigational structure and organization. The blog postings appear in a broad central column. Peripheral areas on a blog's web page offer information and links targeted at a likely reader of the blog, such as links to other blog postings in the network on related topics and user comments. Most (if not all) of the content in these peripheral areas is machine-generated. The ability to publish blogs is, in fact, only a small component of the capabilities of blog networking software, which integrates the blogs across the network, searching and indexing the network's entire content. Searching this vast database of blog content with an intelligent machine agent, relevant content is automatically published to appropriate places in the peripheral navigation of each blog in the network. A blog network publisher will also publish a home page for the entire network. The network home page will typically link to a second tier of organization, which groups blogs by topic and is also updated regularly with titles of recent posts, popular posts, and user comments.

Readers of blogs published as a part of a blog network should be aware that many of these networks are commercial endeavors. The Seed publishing group is responsible for ScienceBlogs.com; Ion Communications publishes Scientificblogging.com. Bloggers publishing on these and many other network blogs have been invited to do so, and some are paid for their work. It is reasonable to suppose that blog networks require that bloggers post regularly and frequently, and perhaps that a given blogger focus on a given topic or set of topics. ${ }^{2}$ With these caveats in mind, there is little reason to believe that blog network publishers censor or regulate the blogs they publish. Bloggers believing that their work is being edited or censored can easily leave the network to publish the blog on their own. This offers an incentive for both blog network publishers

\footnotetext{
${ }^{2}$ I have only been able to obtain hearsay evidence concerning the requirements and benefits of publishing on a blog network. I intend in an upcoming paper to report the results of deeper investigation into this issue.
} 
and non-network blog publishers to maintain freedom of expression on their sites.

\section{Caveat Lector: Reader, Beware the Blogger!}

Nearly all blogs tend to be informal, reflecting the origin of the blog as a kind of diary. Entries are not polished, the idea being to reflect what's happening at the moment, often written in the voice of an unreflective first person or as a set of notes to one's self. This has important consequences for how blog readers ought to assess blog content. Many blog entries are intended to be provocative, and they may reflect a view that is extreme even for the blogger, who may be seen as experimenting with new ideas. A blog is not the best place to find out the settled views of a researcher writing about his or her ideas: A blog provides a place for raising questions, pointing out problems and difficulties, and exploring new formulations. In contrast, a blog may also provide a venue for the blogger to insist upon views held so firmly that he or she would never relinquish or revise them, despite evidence against them deemed compelling by other reasonable people. There are other reasons that blog posts should be carefully assessed as sources of information.

A scientist will typically spend far less time on a blog post than he or she would spend on a paper reporting the results of his or her research or a conference presentation; users commenting on a scientist's blog post may often simply write whatever first comes to mind. Though some blog posts list supporting references, most do not, and there is no expectation among bloggers or their readers that they should. Blogs are not peer-reviewed: In principle, those that allow comments are open to criticism by anyone, but no explicit qualitycontrol procedures exist to keep bloggers honest or to assess their work. Egregious errors and misstatements may persist in blog posts because no one is interested in correcting them, or because the blog is obscure enough so that no one with the needed experience has discovered it.

\section{Some Evolution Blogs}

Bloggers are independent, and blog audiences expect each blogger to express his or her own points of view, share personal experiences and opinions, and reveal his or her quirks. This means that each blog differs from every other in important ways; moreover, it means that most blogs vary from post to post in important ways. A late summer post might present vacation pho- tos, posts at midterm time might reflect on teaching or academic life, and the publication of an important paper in the blogger's area of research might provoke a strong response or set of responses. For this reason, the enterprise of categorizing blogs is risky at best: To borrow from population genetics, each blog might be thought of as a species of its own that exhibits stable polymorphism. No one theme, tone, or subject predominates, each appearing now and again throughout the lifetime of the blog.

Nonetheless, it does not follow that each blog is a sui generis creation, lacking any commonality with other blogs. My view is that there is a set of characteristics, one of which might be exhibited by a given blog at one point in time, another of which might be exhibited by that same blog at a different time. Some blogs might exhibit one of these characteristics more often than it exhibits the others, or rarely exhibit this property, but do so vividly and distinctly. Such a blog may then serve as an exemplar or paradigm of this characteristic. In the remainder of this section, I present four categories for blogs and offer exemplars of each. Accordingly, my claim is not that each blog always exhibits the characteristics of the category in which I place it; my claim is that each such blog has exemplary moments at which it may be used as a reference for comparison in order to determine whether other blogs exhibit that same characteristic.

Because I am using this strategy, the list of blogs below is not intended to be comprehensive. The disorganized nature of the blogosphere and the ephemeral nature of blogs make it difficult to assemble an authoritative directory, in any case. I do list more blogs in the "Amateur" category than is probably required to exemplify it. This is because I believe that blogs of this variety are superior to those of other varieties for the purpose of explaining evolutionary science, one of the chief aims of Evolution: Education \& Outreach, and so, likely to be of interest to its readers. I believe that the blogs listed below form a substantial proportion of a core group of these exemplary explanationproviding blogs. As well, following links on those blogs, the Internet user will be able to visit a large number of similar blogs. I hope this will satisfy bloggers and their audiences, who will probably complain that I have failed to include their favorite blog.

Unless otherwise noted, information about blog authors has been obtained from the blog itself, usually from its "about" page, but sometimes from a blogger's profile, directly linked from the blog's front page. The blog categories, the blogs I place within each, and their URLs appear in Table 1. I would like to take this opportunity to acknowledge that some blogs that have 
Table 1 Categorization of evolution blogs and their URL's. See "Some Evolution Blogs" for an explanation of each category

\begin{tabular}{|c|c|c|}
\hline Category & Blog & Address \\
\hline Professional & $\begin{array}{l}\text { Evolution } \\
\text { The Evolution List } \\
\text { Evolutionary Psychology } \\
\text { The Wild side }\end{array}$ & $\begin{array}{l}\text { http://evolution.freehostia.com } \\
\text { http://evolutionlist.blogspot.com } \\
\text { http://evolpsychology.blogspot.com } \\
\text { http://judson.blogs.nytimes.com }\end{array}$ \\
\hline $\begin{array}{l}\text { Instructive } \\
\text { amateur }\end{array}$ & $\begin{array}{l}\text { Dechronization } \\
\text { The EEB and Flow } \\
\text { The Evilutionary Biologist } \\
\text { Evolutionary Novelties } \\
\text { Evolution Diary } \\
\text { Genomicron } \\
\text { Tree of Life } \\
\text { Why Evolution is True }\end{array}$ & $\begin{array}{l}\text { http://treethinkers.blogspot.com/ } \\
\text { http://evol-eco.blogspot.com/ } \\
\text { http://evilutionarybiologist.blogspot.com/ } \\
\text { http://evolutionarynovelty.blogspot.com/ } \\
\text { http://evolutiondiary.com/ } \\
\text { http://genomicron.blogspot.com/ } \\
\text { http://phylogenomics.blogspot.com/ } \\
\text { http://whyevolutionistrue.wordpress.com/ }\end{array}$ \\
\hline $\begin{array}{l}\text { Organization } \\
\text { and project }\end{array}$ & $\begin{array}{l}\text { Beagle Project } \\
\text { NCSE }\end{array}$ & $\begin{array}{l}\text { http://thebeagleproject.blogspot.com } \\
\text { http://ncseweb.org }\end{array}$ \\
\hline Apostolic & Pharyngula & http://scienceblogs.com/pharyngula/ \\
\hline Imaginative & $\begin{array}{l}\text { The Loom } \\
\text { The Flying Trilobite }\end{array}$ & $\begin{array}{l}\text { http://blogs.discovermagazine.com/loom/ } \\
\text { http://glendonmellow.blogspot.com }\end{array}$ \\
\hline Networks & $\begin{array}{l}\text { Blog Carnival } \\
\text { of Evolution } \\
\text { Research Blogging } \\
\text { Scienceblogs.com } \\
\text { Scientificblogging.com }\end{array}$ & $\begin{array}{l}\text { http://blogcarnival.com/bc/cprof_5028.html and } \\
\text { http://carnivalofevolution.blogspot.com/ } \\
\text { http://researchblogging.org/ } \\
\text { http://scienceblogs.com } \\
\text { http://scientificblogging.com and } \\
\text { http://scientificblogging.com/evolution }\end{array}$ \\
\hline
\end{tabular}

been abandoned may still be of value and may have been exemplary in their day of one or another of the categories I consider below. Nonetheless, I do not list such blogs in order to focus on the state of the art.

\section{Professional}

Writers and teachers count blogs among the tools of their trade. Blogs created for use of such professionals are typically devoted almost entirely to explaining evolutionary science. They are excellent sources of information. Nonetheless, the precision, discipline, generality, depth, and richness of the professional blog are bought at the cost of distance. The professional's blog lacks the expression of personal preference, anecdote, and first-person narrative that characterize the large majority of blogs on evolution.

The Wild Side Olivia Judson. Ph.D., Biological Sciences, Oxford University; author of Dr. Tatiana's Sex Advice to All Creation (New York: Henry Holt, 2002) (Judson 2009). Dr. Judson's blog appears regularly on the web site of the New York Times. She has been on sabbatical since January 2009 and is scheduled to return in "summer 2009"; until then, guest bloggers have been posting on a range of science topics. Posts by
Judson include "Resurrection Science" (25 November 2008), about the completion of a draft sequence of the woolly mammoth's genome; "All Hail the Apple Maggot" (18 November 2008), about speciation in Rhagoletis pomonella; and "Cancer of the Devil" (14 October 2008), about a cancer transmitted by a virus that threatens to drive Tasmanian Devils to extinction, some believe within 25 years. These posts are excellent reading: Crisp, engaging prose driven by puzzles and questions transmits Judson's mastery of her topic to the reader.

The Evolution List Allen MacNeill, MA, Science Education, Cornell University, has taught the "support course for introductory biology at Cornell University since 1976" (Cornell Learning Strategies Center 2009). This remarkable blog posts original content by MacNeill on a range of topics about evolution. Posts are readable, non-technical, analytical, and deep. A significant minority of posts (29 and 22 April 2009, e.g.) engage creationist and intelligent design bloggers in discussion. Some posts (8 and 27 April 2009, e.g.) provide information about basic concepts in evolutionary biology and the history of the discipline. One post (14 April 2009) consists of the full syllabus for a Cornell University course entitled "Evolution: The Darwinian Revolutions." 
Evolutionary Psychology This blog by Allen MacNeill (see "The Evolution List," above) is astonishing in the breadth and depth of the information it provides: an online textbook of evolutionary psychology. MacNeill addresses issues concerning the nature of science and the basic ideas of evolutionary biology; the biology and evolution of behavior, including human mating and sex; and religion and war; models of the human mind. There are also study questions and recommended readings. Blog posts on particular issues are organized by topic. For this reason, this site falls outside of the strict definition of "blog," because the site's general organization is topical. Nonetheless, it is constructed using blog publication tools, and the important elements of its content are communicated in blog posts. This represents an innovative use of the blog form: It is as though MacNeill has looked over his notes on a subject, taken sequentially as he learned about it, and organized them by topic.

Evolution The third of the excellent blogs by Allen MacNeill (see "The Evolution List," above), this blog is one of the materials MacNeill provides for his Cornell University course "The Darwinian Revolutions." Blog posts are thoughtful and accessible. Some are about current events, for instance, US President Obama's authorization of the use of federal funds for embryonic stem cell research (19 March 2009). Others concern the nature of science, such as a review of a recent book about metaphor in science (24 March 2009). He also discusses historical topics, for instance, "Day One of the Evolution Revolution" (2 July 2008). Note that many of the posts to this blog originated at "The Evolution List."

The exceptional part of the blog, however, is not the posts, but rather the links in the right-hand sidebar. All course materials for MacNeill's "The Evolution Revolutions" are available, including the syllabus, essay questions, handouts, and lecture notes. The syllabus lists readings included in the course packet; many of these are available free online. An additional link lists the required books for the course.

\section{Amateur}

Those who create the blogs in this category are not amateur scientists; indeed, most are experienced research professionals. Nonetheless, they are not professional bloggers, and their blogs present them with an opportunity to take a lighter, less formal approach to the topics they know and love. For this reason, many posts to blogs in this category are highly informative expository essays on a range of topics in evolutionary science.
Because their authors pursue blogging as an alternative to their professional work, many posts concern their personal lives and general observations about their profession. Many comment on the mainstream news media's coverage of science, and also on developments in the evolution-creation controversy. Published scientific literature is also discussed regularly. The tone of these blogs is friendly and chatty. Sarcasm or personal attacks on others are rare, although jokes and wit are often on display.

Genomicron T. Ryan Gregory, Ph.D., Evolutionary Biology, U. of Guelph; Assistant Professor, Dept. of Integrative Biology, U. of Guelph; Associate Editor of Evolution: Education \& Outreach. Gregory's blog has moved from place to place, finally finding a home at evolverzone.com, an Internet portal created by Gregory for those looking for information about evolution. Recent (May 2009) posts include "Research Covered by News Media," which links to a cartoon showing that robots and chocolate, among other topics, are those most likely to be reported on by mainstream sources; "Lamarck on Genome Research," commentary about a recent tendency to want to rehabilitate the notion of the inheritance of acquired characteristics; and "Genome Biology and Evolution," about a new online journal. A non-science post discusses Gregory's parents' activities in Zambia promoting musical theater and raising money for a local school.

Evolutionary Novelties Todd Oakley. Assistant Professor at the Dept. of Ecology, Evolution, and Marine Biology, University of California, Santa Barbara; Ph.D., Biology, Duke University (Oakley 2009). Recent posts include "Evolutionary Novelty: Get Milk," (3 May 2009), which summarizes a recent paper in Genome Biology concerning the evolution of lactation in mammals. The reader is immediately alerted to the topic by an image displaying the variety of uses of the "Got Milk" slogan. Remaining true to the mission of educating his readers but using a light touch, Oakley held a contest to determine the best mnemonic for the geologic eras. Two hundred forty nine votes were cast. The winning mnemonic consists of the names of characters and plot elements from the cartoon show "The Family Guy."

Evolution Diary Foo Chee Yuan. No author information is provided on the blog. The blogger republishes news stories on evolution from around the web, including the BBC; Science Daily, at http://www. sciencedaily.com/; and National Geographic. Recent posts concern the discovery of the fossil nicknamed "Ida" (25 May 2009), the X chromosome (25 April 
2009), and the discovery of fossils of a creature claimed to be an ancestor of Tyrannosaurus rex (25 April 2009). Although the blogger contributes original content in responses to user comments, posts consist entirely of the republished articles. Links to the original source of publication of the re-posted article are provided.

Dechronization Susan Perkins, Assistant Curator and Professor at The American Museum of Natural History (American Museum of Natural History 2009); Dan Rabosky, Tom Near, Richard Glor, Ph.D., Organismic and Evolutionary Biology, Harvard, now Assistant Professor at the University of Rochester; Liam Revell, Ph.D. student, Organismic and Evolutionary Biology, Harvard University (Revelle 2009); Boris Igić, Assistant Professor, Biology, University of Illinois, Chicago; Brian Moore, Postdoctoral researcher at The University of California at Berkeley, Integrative Biology (Department of Integrative Biology 2009); and Luke J. Harmon. Posts report and comment on a range of topics including software for phylogenetic analysis, parasites, and the Anolis lizards. Some posts are technical, probably not accessible to the nonspecialist, but most are aimed at a general audience. The posts about research are balanced by lighter interludes. In "More 'Parasites rule" (15 May 2009), Perkins notes that some of the information she relates in the post makes "good creepy stuff for cocktail party or coffee shop evolutionary chit-chat for sure." Glor posted parts of a final exam he recently administered to his "Tree of Life" course at the University of Rochester. Those commenting on this post struggle with the answers.

This blog takes its name from George Gaylord Simpson's novel, The Dechronization of Sam McGruder (New York: St. Martin's, 1996), in which a geologist falls back in time, and, realizing that he will never be able to make it back to his former present, endeavors to make a record of what he sees so that humans, once they come into being, will be able to learn from his experiences.

The EEB and Flow Birte Matthiessen; Jonathan Davies; Martín A. Nũnez, Ph.D., University of Tennessee, postdoctoral researcher in Biology, University of Central Florida (Nũnez 2009); Marc Cadotte, Ph.D., University of Tennessee, Postdoctoral Associate, National Center for Ecological Analysis and Synthesis, Santa Barbara, California (Cadotte 2009); Brad Murray, Ph.D., Macquarie University, Senior Lecturer, University of Technology Sydney, Australia (Murray 2009); and Rachel Shulman. This international bunch blogs on evolutionary ecology. They report on and assess recent journal publications in ecology and related disciplines. Recent postings address papers about forest fires, plant adaptations to herbivores, and the role of hurricanes in global warming (all May 2009). Entries are short and easy to understand. "EEB" stands for "ecology and evolutionary biology." This blog is a part of the researchblogging.org network.

Tree of Life Jonathan A. Eisen. Academic Editor in Chief of PLOS Biology, Professor and holder of many appointments in life sciences departments at University of California, Davis (Genome Center 2009). Recent posts (May 2009) concern trends and controversies in life sciences academic publishing, the announcement of a lecture on population genetics and an art show about Darwin at UC Davis, and links to other Internet resources about science and science teaching. The majority of Eisen's posts concern publishing in science, but an important minority explains ideas and discoveries in evolution.

The Evilutionary Biologist John Dennehy. Ph.D., Biology, Clark University, Assistant Professor, Biology Department, Queens College, City University of New York (Dennehy 2009). Posts about the interaction of scientists with the media, recent fossil discoveries, and Charles Darwin's scientific work. A recent (1 May 2009) post entitled "Biology of B-Movie Monsters" comments on and links to an online article that puts biological principles into play to answer such questions as "Who would win, if a miniaturized man confronted a spider?" This blog is a part of the researchblogging.org network.

Why Evolution is True Posts to this blog often lack attribution, and no "about" page describes the author or authors. Myers (http://scienceblogs.com/ pharyngula/2008/10/why_evolution_is_true.php) states that the author is Jerry Coyne, which would not be surprising; Coyne recently authored Why Evolution is True (New York, Viking: 2009), and the anonymous blogger often uses the first person when discussing the author of that book. Like "Evolutionary Psychology" (see above), the home page of "Why Evolution is True" links to areas of the site each addressing a different topic, each of these areas of the site consisting of dateordered posts. "Adaptations," "Articles," and "News" all contain informative posts, such as "How the Giraffe Got its Long Neck" (17 and 21 May, 2009), attributed to blogger Greg Mayer. A 27 May 2009 post directs readers to a Scientific American paper on the evolution of house cats. The "Intelligent Design and Creationism Watch" section contains posts about the placement of creationist bookmarks in bookstore copies of Why Evolution is True (30 May 2009) and comments on a 
Spectator article in which the author claims "that intelligent design grew out of science, not religion" (4 May 2009). Some of the posts in this section are so strongly worded that this blog bears some characteristics of blogs in the "Apostolic" category (see below).

\section{Organization and Project}

Many organizations publish a blog to communicate with their supporters and the general public. The organization can inform its members of its response to current events, its plans for the future, or the success of recent endeavors. The blog need not be as impersonal as a quarterly report or newsletter because the blogger or bloggers can speak from a first-person point of view. Readers can see the organization from the inside by identifying with the blogger. Similarly, members of a collaborative group might publish a blog chronicling their progress toward the completion of their project.

Beagle Project Blog Richard Carter, Karen James, Elke Watts, Peter Mcgrath. Posts to this blog are written by people working on the Beagle Project, the aim of which is to build a replica of the H.M.S. Beagle and to pilot this replica along the same path that Captain Fitzroy took the original Beagle (see http://www. thebeagleproject.com/). McGrath is the "joint founder and webmaster of the H.M.S. Beagle project" and a "professional yacht skipper." James, a postdoctoral researcher in the Botany Department at London's Natural History Museum, coordinates the Museum's Darwin Bicentennial events, in addition to working on the Beagle project (Natural History Museum 2009). Watts informs Internet users that her name is an anagram for "Sweet Talk"; Carter publishes a number of blogs. Posts in recent months (April-May 2009) concern the sale of t-shirts to help fund the Beagle project; space and ocean exploration; a biography of Darwin, in the form of a graphic ("cartoon") work; and a fascinating account of the original Beagle's keel repair, performed en route, in South America. The posting shows a satellite photo of the site of the keel repair and a recent photograph of the beach where it took place.

National Center for Science Education The National Center for Science Education publishes regular updates and alerts about the status of efforts to keep creationism and other nonscientific, religious topics from being taught in science classes, an aim central to the Center's mission. Posts appear on the Center's home page. They are unaccompanied by a byline and have the character of a wire service report-brief, informative, and unadorned. The objectivity and focus of these short posts are due to their restricted purpose. In this sense, they are like the professional blogs discussed above.

Apostolic

"Apostolic" captures an important element of many blogs. On the one hand, an apostle is a committed follower, someone devoted to a cause; on the other hand, an apostle is a leader responsible for advancing that cause. Many blogs-some are devoted almost entirely to this-take up the cause of science as a way of knowing and evolutionary biology as true and most salient to understanding our place in the universe, taking both science as a whole and evolutionary biology more particularly as the only basis for answering the question "How should one live?" Almost as though this position requires the existence of equally committed opponents, there are many, many apostles of religion, creationism, and its younger cousin the ID ("intelligent design") movement ready to engage. The blogosphere is one of the bloodiest fields on which the two foes meet. Insults, personal attacks, and repeated declarations that the opponent's point of view is uncivil, foolish, and dangerous are to be expected. The blog publishing model offers the blogger a means of expressing his or her feelings at the height of their intensity. Posts are rendered in a strong first-person voice. Activities of the blogger and his or her colleagues at conferences, debates, and on campus are also reported from the first person.

Pharyngula P. Z. Myers, Associate Professor, Biology, University of Minnesota, Morris. Clearly the paradigm of the apostolic blog, Myers is uncompromising in his opposition not only to creationism and intelligent design but to religious belief more generally. This often takes his posts beyond evolution and science into politics; consider, for instance, his recent (30 May 2009) post about whether same-sex marriage ought to be legalized in New Hampshire. Posts can sometimes be ironic. Another 30 May 2009 post asks “Ok, who's the wise guy who gave one of our creationists a writing gig at The Onion?" Following a link in the post to The Onion $^{3}$ brings the reader to a mock news story ridiculing someone using the kinds of argumentative tactics Myers believes that creationists often use. The more literal-minded might take the post to indicate that a creationist had in fact been hired by The Onion,

\footnotetext{
${ }^{3}$ The Onion is a parody of serious newspapers, publishing stories mocking those published in mainstream news media.
} 
which would now be publishing stories from his or her perspective.

Myers' antipathy for creationists often takes a personal turn. In another post of 30 May 2009, Myers quotes a "secular principle," according to which someone ought to commit to "strive to respect the dignity of all people." Myers comments that "I deal with too many creationists, and those are people without much dignity to respect." Another post of the same day targets the philosopher Alvin Plantinga. Myers relates his experiences reading Plantinga's work. "It's very bizarre stuff, and every time I get going on one of his papers I hit some ludicrous, literally stupid claim that makes me wonder why I'm wasting time with this pretentious clown, and I give up, [and] throw the paper in the trash." Quoting a passage in which Plantinga reports the results of some calculations with probabilities, Myers asks, "First, an amusing aside: [Plantinga acknowledges] the assistance of someone else in doing those calculations. He needed help from an expert to multiply simple probabilities? Does being a philosopher mean you're incapable of tapping buttons on a calculator?"

To be clear, many of Myers' posts provide arguments against the creationist positions he so disapproves of. Myers does not restrict himself to insulting Plantinga, but also advances arguments against him, quoting Plantinga at length. I do not mean to claim or imply that Myers provides no useful information about evolutionary science. Having said this, I do want to claim that the blogs listed in the "Amateurs" category above are a better source for information about science. The value of Myers' blog as a source of information comes indirectly from his engagements with his opponents. A reader of Myers' blog will learn quickly about the central protagonists in the debate, the central points over which they contend, the kinds of arguments and strategies they use, and their political and cultural affiliations and identifications.

\section{Imaginative}

The personalities of scientists and those interested in science and their gatherings at scientific meetings make worthy topics for a blog; so do the creative works representing or inspired by evolutionary science. Accordingly, many blogs explore just these phenomena. I hesitate to call blogs focused on art and culture "imaginative," because doing so suggests a contrast with the other categories of blogs as "non-imaginative." I see science as an imaginative endeavor, even at its most arcane. Perhaps "evolution culture" would be a better name for this category. The important point is that these blogs look at evolution and related science from the point of view of the disciplines of visual art, music, or writing, rather than from the point of view of those disciplines aimed directly at generating new scientific knowledge.

The Loom Carl Zimmer. Freelance writer, author of Evolution: The Triumph of an Idea, At the Water's Edge, and The Smithsonian Intimate Guide to Human Origins (CarlZimmer.com 2009); winner of the National Academies Science Communication Award for "diverse and consistently interesting coverage of evolution" (National Academies 2007). This blog is eminently readable, and there is much to read: Zimmer posts several times per day on most days. Recent posts (May 2009) concern the controversy over the fossil known as "Ida," with particular concern for the press coverage of its discovery; a summary of an article in Cell about mouse research aimed at discovering more about the evolutionary origin of the human brain; and a list of nominees for the Royal Society Science Book prize. What distinguishes Zimmer's blog from those in the amateur category is that he has a keen sense of what aspects of the interplay between science and culture are particularly likely to illuminate both. For instance, his post entitled "Grandma-Ding" (15 May 2009) marks the occasion of the 40th anniversary of Philip Roth's Portnoy's Complaint, which describes the "grandmother cell": "What if a neuron in your head only responded to the sight of your grandmother?" This connects with puzzles for evolutionists about how particular individuals are recognized, which is a necessary condition for the evolution of many forms of altruism. As it happens, Zimmer points out, outlandish as it might seem, the very capability Roth imagines-a particular capacity for recognizing one's grandmother-may well be a part of our neurological endowment. A second of Zimmer's pursuits that is both novel and rich, his "Science Tattoo Emporium" (http : / / blogs . discovermagazine . com/loom/ science tattoo-emporium/), collects photographic documentation of body art inspired by science, much of it built around themes and images from evolutionary science. At present, the gallery spans 22 pages.

Flying Trilobite Glendon Mellow, freelance artist. In the "Art Monday" series of posts, Mellow describes the processes by which he composed stunning artwork, much of it used in the banners of other blogs. He explains the creation of each work in a step-by-step manner, showing how the different elements of each are separately conceptualized, composed, and synthesized to form the completed work. The posts 
concerning "Migrations" at http://glendonmellow. blogspot.com/2009/05/art - monday-migrations-bannerconcepts.html are excellent examples of the breadth, depth, and precision of Mellow's account of his art practice. The artworks are available for use by the public under a Creative Commons license.

\section{Networks}

As discussed in the main text of this article above, there are blog publishers that create networks of blogs. The networks listed here link together blogs in all areas of science; four are described here.

Blog Carnival of Evolution A "Blog Carnival" works in the following manner. Bloggers and blog readers interested in a particular topic identify posts on that topic that they find particularly interesting or notable. A person selecting a post submits a link for that post to a form on a web site created for the purpose of recording recommended posts. At some regular interval, say, every month, links to posts that have been submitted by users are integrated into a single blog post by a volunteer blogger. This single post is often amusing - the task is to write a blog post with phrases able to serve as a link to dozens of other posts. This single post can be used as a portal to all those it links to, offering users an easy entry point into a community-generated collection of recent discussion. Blog carnivals are registered at http://blogcarnival.com; the Blog Carnival of Evolution may be found at http:// blogcarnival.com/bc/cprof_5028.html. It also has a home page at http://carnivalofevolution.blogspot.com, where an archive of all past carnivals can be found. As of May 2009, there have been 11 Carnivals. The Carnival is administered by Daniel D. Brown, whose own blog can be found at http://biochemicalsoul.com.

Researchblogging.org This network does not host or publish blogs, but provides a mechanism for organizing them: It serves as an Internet portal for blog posts commenting on peer-reviewed literature. Indeed, these posts may be thought of as an extension of the peer review process itself. The articles discussed in each post are vetted by journal editors and referees before publication; after publication, blogs in the Researchblogging.org network review them again, this time in an informal manner, online. Bloggers include themselves in the network by tagging their posts with code provided by the network organizers. In addition to displaying a badge identifying the post as being about peer-reviewed research, this code results in the post's being included in the network. Users can locate posts on topics of interest by searching or by following links to subject areas from the network's home page. Although users can navigate to a section of the site for biology, no separate section exists for evolution. The central area on the network home page lists recent posts. The publisher of this network is Research Blogging, "a community-run non-profit organization" (Research Blogging 2008).

Scienceblogs.com Published by the Seed Media Group, this network hosts and publishes blogs, which have World Wide Web addresses ending in "scienceblogs.com." The network homepage serves as a portal to the network's blog content. A horizontally oriented navigation bar offers readers links to blogs about physical science, environment, humanities, education, politics, medicine, brain and behavior, technology, and information science. A central area of the home page, called "What We're Talking About" lists recent posts from blogs in the network that concern a topic selected (presumably) by the blog publishers. On 30 May 2009, that topic was "Trust and Distrust in the Vaccine Debate." Less central areas list posts in each of the subject areas listed above; sidebars provide more links to recent posts, New York Times articles about science, and a column entitled "Basics"; on 30 May 2009, this presented links to blog postings from the network's archives about avian flu.

ScientificBlogging.com Like Scienceblogs.com, this network hosts and publishes blogs; the addresses of these blogs end with "scientificblogging.com." Published by Ion Communications, LLC., the home page of this network serves as a portal to the blogs in the network. Users can look for blogs by following links to subject-area collections. Subjects are physical sciences, earth sciences, life sciences, medicine, social sciences, and culture. A subsection about evolution can be found by following the "Life Sciences" link. Sidebars on the home page display lists of frequently read posts and user comments. A prominent "Featured Articles" display indicates (and links to) recent postings, presumably deemed to be important by the publishers.

\section{Concluding Remarks: What use Blogs?}

What kinds of questions can blogs about evolution best answer? What role might a blog play in someone's research process? In keeping with my caveat above ("Caveat lector: Beware the blogger"), blogs are not the best source for authoritative information about evolution. For this, reference works, textbooks, and peer-reviewed articles in professional journals are the best source. The blogs by Allen MacNeill are an 
exception to this, because his blogs present teaching materials; still, readers should be aware that even course materials such as MacNeill's are intended for use in the context of a broader set of resources and experiences: Lectures and class discussion supplement lecture notes, as do one-on-one meetings and discussions with fellow students. Evaluation by means of exams and essay assignments focuses the student on key themes in the course that may not be readily apparent to someone not completing them, or one completing them outside the context of the course. Amateur blogs and regular columns such as Olivia Judson's also explain ideas, facts, and discoveries about evolution, and such posts are excellent sources of information. They are not, in general, the best source for information about evolutionary science, however, because they are not systematic-posts concern just the topics that the blogger finds interesting - and their main scheme of organization is chronological, not topical. The researcher would be better served by reference works and the other kinds of resources mentioned above for in-depth study.

Research and learning require more than coming to understand a topic, collecting facts, or making and evaluating interpretations. One must discover terms and concepts with which to pose questions, identify areas of uncertainty and interest to practitioners of the field of inquiry, and generate one's own questions and sketch their answers. Blogs can play an important role in these stages of the research process. The central kinds of questions that blogs can answer are those such as the following: "What are people talking about?" "What are the opposing 'camps' in the range of controversies among evolutionary biologists and their discontents, and who identifies with which camp?" The network of posts created by links between them and the "blogroll" listing of blogs facilitates a rapid survey of a broad range of positions and ideas about topics currently of interest among scientists. A blog post's references to peer-reviewed works and other information resources are good sources for leads. Blogs such as Zimmer's or Mellow's ("Imaginative") blogs can reorient one's thinking. The need to answer these kinds of questions arises at all stages of the research process. At the start, one needs to think broadly in order to generate ideas for further refinement; well into the project, roadblocks and stalls must be overcome; and nearer to the end, the researcher must refine his or her language and presentation of the relevance and motivation for the research project. Because bloggers frequently and vigorously define and take positions in controversy, the researcher is strongly advised to follow many regularly, remaining party to the conversation as it occurs-and indeed, is urged, should he or she be inclined, to take advantage of the many free and user-friendly tools available, and add his or her own voice.

\section{References}

American Museum of Natural History. PEOPLE. http://malaria. amnh.org/People.html. Accessed 31 May 2009.

Cadotte M. Home. http://www.nceas.ucsb.edu/ cadotte/ (2009). Accessed 31 May 2009.

CarlZimmer.com. Bio. http://carlzimmer.com/bio.html (2009). Accessed 31 May 2009.

Cornell Learning Strategies Center. LSC faculty and staff. http:// lsc.sas.cornell.edu/lscstaff.html (2009). Accessed 31 May 2009.

Dennehy B. Curriculum vitae. http://dennehylab.bio.qc.cuny. edu/PDFs/JJ\%20Denneyhy\%20CV.pdf (2009). Accessed 31 May 2009.

Department of Integrative Biology. Member profile. http://ib. berkeley.edu/people/faculty/person_detail.php?person $=423$ (2009). Accessed 31 May 2009.

Genome Center. Faculty. http://genomics.ucdavis.edu/faculty. html (2009). Accessed 31 May 2009.

Judson O. Dr. Tatiana's sex advice to all creation-about the author. http://www.drtatiana.com/author.shtml (2009). Accessed 31 May 2009.

Murray B. http://headhonchobrad.blogspot.com/ (2009). Accessed 31 May 2009.

National Academies. 'In Search of Memory' wins 2007 best book award from the national academies.... http://www8. nationalacademies.org/onpinews/newsitem.aspx? RecordID= 10012007b (2007). Accessed 31 May 2009.

Natural History Museum. Dr Karen E James. http://kejames. com/nhm/ (2009). Accessed 31 May 2009.

Nũnez MA. Curriculum Vitae of Martín Andrés Nũnez. http://web.utk.edu/ mnunez/NunezCV (2009). Accessed 31 May 2009.

Oakley T. Curriculum vitae. http://www.lifesci.ucsb.edu/eemb/ faculty/oakley/oakley_cv.pdf (2009). Accessed 31 May 2009.

Research Blogging. About us. http://researchblogging.org/static/ index/page/about (2008). Accessed 31 May 2009.

Revelle LJ. Curriculum vitae. http://anolis.oeb.harvard.edu/ 〜iam/cv/LJRevell_CV.pdf (2009). Accessed 31 May 2009. 